\title{
Electrocatalytic Oxidation of Hydrogen Peroxide Based on the Shuttlelike Nano-CuO-Modified Electrode
}

\author{
Geng Yang, Fu Chen, and Zhousheng Yang \\ College of Environmental Science and Engineering, Anhui Normal University, Wuhu 241000, China \\ Correspondence should be addressed to Zhousheng Yang, yzhoushe@mail.ahnu.edu.cn
}

Received 12 August 2011; Revised 20 October 2011; Accepted 20 October 2011

Academic Editor: Suna Timur

Copyright () 2012 Geng Yang et al. This is an open access article distributed under the Creative Commons Attribution License, which permits unrestricted use, distribution, and reproduction in any medium, provided the original work is properly cited.

$\mathrm{CuO}$ nanocrystals were prepared with hydrothermal synthesis method. The morphology of the nano-CuO was characterized by scanning electron microscopy. The prepared shuttlelike $\mathrm{CuO}$ nanocrystals were modified to glass carbon electrode (GCE) to form nano-CuO/GCE modified electrode. The obtained modified electrode showed an excellent electrocatalytic property towards hydrogen peroxide in $0.01 \mathrm{M} \mathrm{NaOH}$ containing $0.09 \mathrm{M} \mathrm{KCl}$ electrolyte. Under the optimal experiment conditions, the electrocatalytic response current of this sensor was proportional to the $\mathrm{H}_{2} \mathrm{O}_{2}$ concentration in the range of $0.02 \mu \mathrm{M} \sim 250 \mu \mathrm{M}$ with a detection limit down to $7 \mathrm{nM}$ (signal/noise =3). The sensitivity was calculated to be $227 \mu \mathrm{A} / \mathrm{mM}$. The $\mathrm{H}_{2} \mathrm{O}_{2}$ sensor exhibited low detection limit, fast response time, and good reproducibility and could be applied to determine hydrogen peroxide.

\section{Introduction}

Among numerous biological, chemical, environmental, pharmaceutical, and clinical studies, hydrogen peroxide plays a fundamental role as an oxidizing, bleaching and sterilizing agent [1]. There are a variety of methods with respect to development for the detection of hydrogen peroxide, such as spectrophotometry [2,3], fluorimetry [4], chromatography $[5,6]$, chemiluminescence $[7,8]$, and titrimetry [9]. Compared with these methods, electrochemical techniques have inherent advantages of simplicity, ease of miniaturization, high sensitivity, and relatively low cost and could be applied to determine $\mathrm{H}_{2} \mathrm{O}_{2}[10,11]$. Because of slow electrode kinetics and high overpotential during redox reaction [12], it was usually difficult to test $\mathrm{H}_{2} \mathrm{O}_{2}$ with a conventional electrode. Here, the preparation of chemically modifying electrode with catalytic effect was of valuable significance. Pournaghi-Azar et al. [13] have described the nonelectrolysis preparation path of the $\mathrm{PB}$ films on the $\mathrm{Al}$ surface covered by metallic palladium particles $(\mathrm{Pd} / \mathrm{Al})$ with the two-step chemical modification and studied the electrochemical behavior of $\mathrm{H}_{2} \mathrm{O}_{2}$ reduction on the $\mathrm{PB} / \mathrm{Pd}-\mathrm{Al}$ electrode as an improved electrocatalyst. This sensor exhibited good characteristics via improved stability and electrocatalytic ability. Kumar and Chen [14] prepared poly (p-aminobenzene sulfonic acid-) (PABS-) modified glassy carbon electrode via the electrochemical deposition, PABS was strongly and irreversibly adsorbed onto GC electrode surface, and the PABS-modified electrode was successfully utilized as an enzyme-less amperometric sensor for detection of $\mathrm{H}_{2} \mathrm{O}_{2}$. The sensor showed potent electrocatalytic activities and improved electron transfer abilities.

Nanoparticles as modification materials have been extensively employed in various fields owing to the small size, large surface area, and some other especial properties. Numerous nanometal oxides, such as manganese dioxide [15], nickel oxide [16], zinc oxide [17], and cobalt oxide [18], have attracted considerable interest in the analytical area. Among those nanoparticles, nano-CuO has earned more and more interests thanks to its distinctive properties [19, 20], such as high stability and good electrical properties. Different synthetic methods have been studied for the preparation of $\mathrm{CuO}$ nanoparticles with various morphologies, including nanowire, nanosheet, nanorod, and nanoflower. McAuley et al. [21] synthesised $\mathrm{CuO}$ nanorod agglomerates and prepared the nano-CuO-modified electrode by dropping it onto the electrode. The electrochemical behavior of hydrogen peroxide on the nano-CuO-modified electrode was studied and a limit of detection of $0.22 \mu \mathrm{M}$ was obtained. Song et al. [22] reported that the $\mathrm{CuO}$ nanoflower film could be directly 
fabricated in a single step by the simple surface chemical oxidation of copper foil under hydrothermal condition and then used as active electrode material of nonenzymatic electrochemical sensors for $\mathrm{H}_{2} \mathrm{O}_{2}$ detection. Large surface-tovolume ratio and high efficient electron transport property of $\mathrm{CuO}$ nanoflowers electrode have enabled stable and highly sensitive performance for the nonenzymatic $\mathrm{H}_{2} \mathrm{O}_{2}$ sensor with a detection limit of $0.167 \mu \mathrm{M}$. The electrocatalytic activities of nano- $\mathrm{CuO}$ to $\mathrm{H}_{2} \mathrm{O}_{2}$ were influenced by its morphology and structure.

In the paper, a shuttle-like $\mathrm{CuO}$ nanocrystals were prepared according to the reported method [23]. The obtained shuttlelike nano- $\mathrm{CuO}$ was immobilized successfully onto the glassy carbon electrode (GCE) via adsorption effect to form the nano-CuO/GCE-modified electrode. The electrochemical behavior of hydrogen peroxide on the modified electrode was explored. The shuttlelike nano- $\mathrm{CuO}$ could obviously improve electron transfer abilities between $\mathrm{H}_{2} \mathrm{O}_{2}$ molecules and electrode. The related electrochemical parameters were obtained. The fabricated modified electrode showed an excellent electrochemical response towards hydrogen peroxide in $0.01 \mathrm{M} \mathrm{NaOH}$ containing $0.09 \mathrm{M} \mathrm{KCl}$ solution. Compared with other nano-CuO-modified electrodes employed as $\mathrm{H}_{2} \mathrm{O}_{2}$ sensors, it showed remarkably lower detection limit $(7 \mathrm{nM})$ and higher analytical sensitivity. The proposed sensor could be used to detect quantitatively hydrogen peroxide.

\section{Experimental}

2.1. Reagent and Materials. Hydrogen peroxide (30\% (v/v) aqueous solution) was purchased from Sinopharm Chemical Reagent Co., Ltd. The stock solutions were prepared fresh with doubly distilled water. All other reagents were purchased from Shanghai Chemical Reagent Company and were of analytical grade and used without further purification. Doubly distilled water was used throughout the experiments. The supporting electrolyte we used in this experiment was $0.01 \mathrm{M} \mathrm{NaOH}$ solution containing $0.09 \mathrm{M} \mathrm{KCl}$.

2.2. Apparatus and Measurements. All the electrochemical measurements including cyclic voltammetry (CV) and amperometric response (i-t) were carried out with $\mathrm{CHI} 660 \mathrm{~A}$ electrochemical workstation (Chenhua Instruments Co., Shanghai, China). A conventional three-electrode system was employed. A bare glass carbon electrode (GCE, Ø3.0 mm) or nano-CuO-modified GCE was used as the working electrode, and an $\mathrm{Ag} / \mathrm{AgCl}(\mathrm{KCl}, 3.0 \mathrm{M})$ electrode and a platinum wire electrode were used as the reference electrode and the counter electrode, respectively. A magnetic stirrer provided the convective transport during the amperometric measurements. All experiments were performed at room temperature. Scanning electron microscopy (SEM) was obtained on S-4800 field emission scanning electron microanalyser (Hitachi, Japan).

2.3. Preparation of the Nano-CuO-Modified Electrodes. The preparation of the nano- $\mathrm{CuO}$ was performed as follows: in the first place, $0.25 \mathrm{~g} \mathrm{Cu}\left(\mathrm{CH}_{3} \mathrm{COO}\right)_{2} \cdot \mathrm{H}_{2} \mathrm{O}$ and $0.77 \mathrm{~g}$

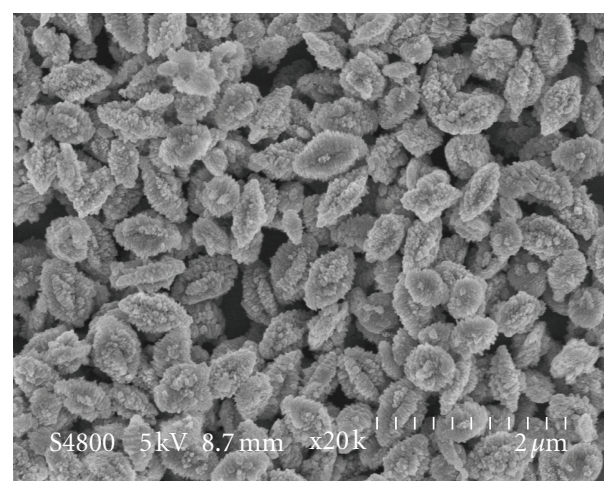

FIgURE 1: SEM image of shuttlelike $\mathrm{CuO}$ nanocrystal film.

cetyltrimethylammonium bromide (CTAB) were put in a $60 \mathrm{~mL}$ teflon-lined stainless steel autoclave, then $40 \mathrm{~mL}$ doubly distilled water was poured into the autoclave with stirring. Afterward, $4 \mathrm{~mL}, 0.5 \mathrm{M} \mathrm{NaOH}$ was tardily added into the above solution under stirring. Completing all the above steps, it was necessary to make sure that the autoclave was tightly sealed. Meanwhile, the temperature of autoclave was maintained at $120^{\circ} \mathrm{C}$ for $12 \mathrm{~h}$ and then cooled to room temperature naturally. The precipitate was centrifuged and washed with doubly distilled water and absolute ethanol several times over and over, then dried in vacuum at $70^{\circ} \mathrm{C}$ for several hours.

Prior to the modification, the GCE was mechanically polished with alumina powder $\left(\mathrm{Al}_{2} \mathrm{O}_{3}, 0.05 \mu \mathrm{m}\right)$ up to a mirrorlike, then cleaned by ultrasonication in water and ethanol, and then rinsed with doubly distilled water and dried. A nano-CuO dispersion solution $\left(0.8 \mathrm{mg} \mathrm{mL}^{-1}\right)$ was prepared with dispersing ultrasonication nano- $\mathrm{CuO}$ particle into doubly distilled water. A certain volume dispersion solution was dropped onto surface of a clean GCE, and then electrode was dried for 30 minters under room temperature to evaporate solvent, leaving the nano-CuO particle immobilized onto the surface of electrode.

\section{Results and Discussion}

3.1. Surface Characterizations. Via scanning electron microscopy (SEM), the morphologies and structures of the surface film of the modified electrode was characterized. Figure 1 shows scanning electron microscopy image of nano-CuO film. From the figure, the shuttlelike nano- $\mathrm{CuO}$ was evenly distributed on surface of electrode. The $\mathrm{CuO}$ nanocrystals looked like shuttles; furthermore, the sizes were similar and the distribution was also average on the whole. And the nano- $\mathrm{CuO}$ nanocrystals took on large specific surface area.

A Nyquist diagram of electrochemical impedance spectrum was an effective way to measure the electron-transfer resistance. Figure 2 shows electrochemical impedance spectra of bare GCE and nano-CuO/GCE in $1 \mathrm{M} \mathrm{KCl}$ in the presence of $1 \mathrm{mM}\left[\mathrm{Fe}(\mathrm{CN})_{6}\right]^{3-/ 4-}$ as the redox probe. As seen in Figure 2, curve a was a Nyquist plot of a bare GCE in $1 \mathrm{mM}\left[\mathrm{Fe}(\mathrm{CN})_{6}\right]^{3-/ 4-}$. It exhibited an almost straight line, which implied an extremely low electron-transfer resistance 


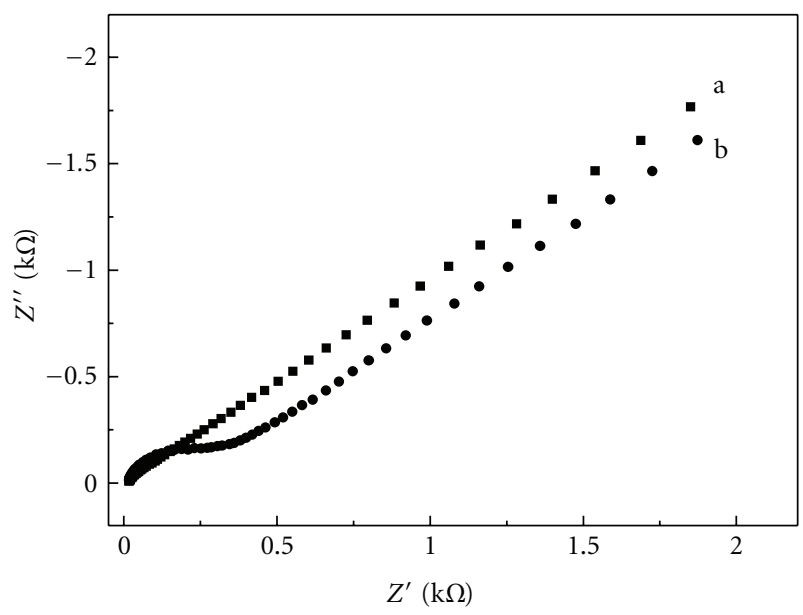

FIgURE 2: Electrochemical impedance spectra of bare GCE (a) and nano-CuO/GCE (b) in $1 \mathrm{mM}\left[\mathrm{Fe}(\mathrm{CN})_{6}\right]^{3-/ 4-}+1 \mathrm{M} \mathrm{KCl}$.

to the redox probe. After a modification with nano- $\mathrm{CuO}$ film, the electron-transfer resistance reached a higher value and the interfacial $R_{\text {et }}$ increased, which was due to the impediment of electron transfer in the presence of the nano$\mathrm{CuO}$ film. It indicated that the $\mathrm{CuO}$ shuttlelike nanocrystals were immobilized on the GCE successfully.

3.2. Electrochemical Characteristics of the Sensor. The electrochemical behaviors of $\mathrm{H}_{2} \mathrm{O}_{2}$ on nano-CuO/GCE were explored. As shown in Figure 3(a), there was no electrochemical response to $\mathrm{H}_{2} \mathrm{O}_{2}$ on the bare GCE in $0.01 \mathrm{M}$ $\mathrm{NaOH}+0.09 \mathrm{M} \mathrm{KCl}$ solution. However, there was a large anodic peak of $\mathrm{H}_{2} \mathrm{O}_{2}$ on the nano- $\mathrm{CuO} / \mathrm{GCE}$ under the same experimental condition, and the potential of anodic peak was at $0.19 \mathrm{~V}$. For comparison, the cyclic voltammetric experiment was performed with nano-CuO/GCE in $0.01 \mathrm{M}$ $\mathrm{NaOH}+0.09 \mathrm{M} \mathrm{KCl}$ solution not containing $\mathrm{H}_{2} \mathrm{O}_{2}$. There was no obvious redox peak on CV curves between the given potential range (figure. not shown). A large anodic peak indicated that $\mathrm{H}_{2} \mathrm{O}_{2}$ could yield redox reaction on the nano- $\mathrm{CuO} / \mathrm{GCE}$. Probable mechanisms could be suggested to explain the anodic oxidation of $\mathrm{H}_{2} \mathrm{O}_{2}$ in alkaline medium:

$$
\mathrm{H}_{2} \mathrm{O}_{2}+2 \mathrm{OH}^{-}-2 \mathrm{e} \longrightarrow 2 \mathrm{H}_{2} \mathrm{O}+\mathrm{O}_{2} \text {. }
$$

The dependence of $\mathrm{H}_{2} \mathrm{O}_{2}$ anodic peak current on scan rates was examined. Figure 4 showed the cyclic voltammograms of $\mathrm{H}_{2} \mathrm{O}_{2}$ on the nano- $\mathrm{CuO}$ film in $0.01 \mathrm{M} \mathrm{NaOH}+$ $0.09 \mathrm{M} \mathrm{KCl}$ containing $0.1 \mathrm{mM} \mathrm{H}_{2} \mathrm{O}_{2}$ solution. The experimental result indicated that the anodic peak current of $\mathrm{H}_{2} \mathrm{O}_{2}$ $\left(I_{\mathrm{pa}} / \mu \mathrm{A}\right)$ was proportional to the square root of scan rate $\left(v / \mathrm{Vs}^{-1}\right)\left(I_{\mathrm{pa}}=-74.05 v^{1 / 2}-1.15, R^{2}=0.999\right)$, suggesting that the electrode process was controlled by diffusion as expected for a catalytic system.

3.3. Optimization of the Experiment Conditions. In order to optimize the electrocatalytic response to $\mathrm{H}_{2} \mathrm{O}_{2}$ on the nano-CuO/GCE, the effect of $\mathrm{NaOH}$ concentration and the nano-CuO film thickness on anodic peak current was

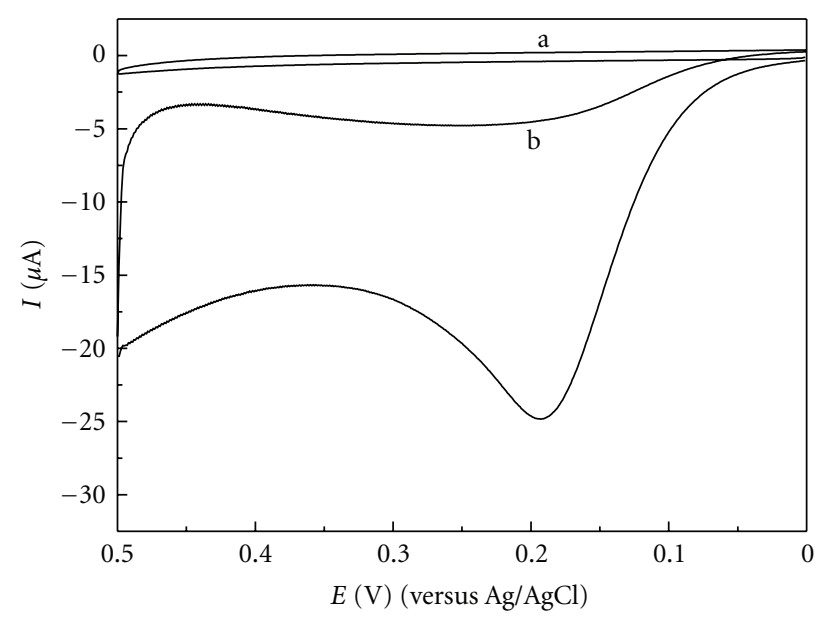

Figure 3: Cyclic voltammograms of bare GCE (a) and nano$\mathrm{CuO} / \mathrm{GCE}(\mathrm{b})$ in $0.01 \mathrm{M} \mathrm{NaOH}+0.09 \mathrm{M} \mathrm{KCl}$ solution containing $0.1 \mathrm{mM} \mathrm{H}_{2} \mathrm{O}_{2}$. Scan rate: $0.10 \mathrm{Vs}^{-1}$.

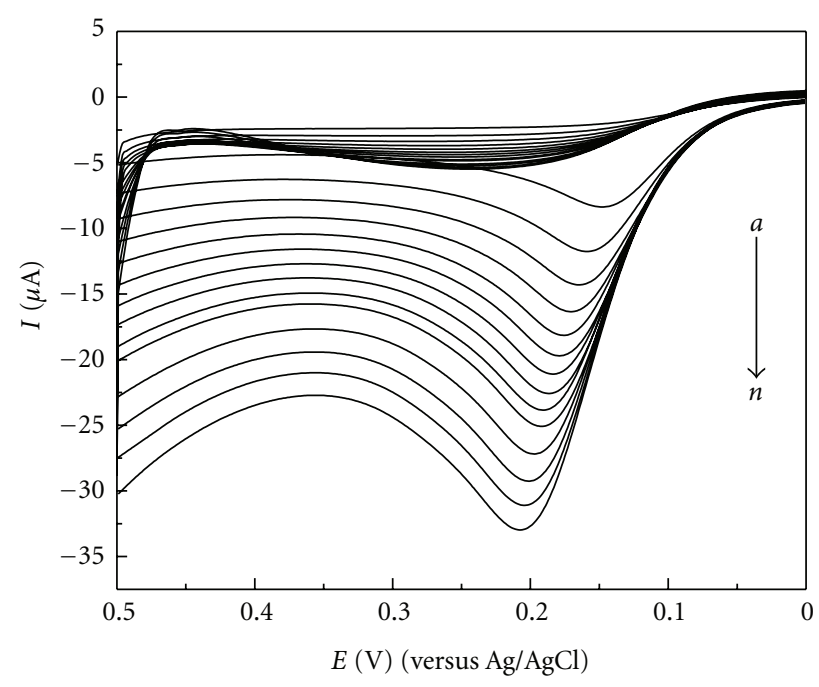

FIGURe 4: Cyclic voltammetric curves of nano-CuO/GCE in $0.01 \mathrm{M}$ $\mathrm{NaOH}+0.09 \mathrm{M} \mathrm{KCl}$ solution containing $0.1 \mathrm{mM} \mathrm{H}_{2} \mathrm{O}_{2}$ at different scan rates. Scan rates: $(a) \longrightarrow(n)$ 0.01, 0.02, 0.03, 0.04, 0.05, 0.06, $0.07,0.08,0.09,0.10,0.12,0.14,0.16$, and $0.18, \mathrm{Vs}^{-1}$, respectively.

explored. Maintaining system ion concentration $0.1 \mathrm{M}$, the concentrations were changed from 0.001 to $0.1 \mathrm{M}$ for $\mathrm{NaOH}$ and from 0.099 to 0 for $\mathrm{KCl}$. With increment of $\mathrm{NaOH}$ concentration, anodic peak current of $\mathrm{H}_{2} \mathrm{O}_{2}$ increased. When $\mathrm{NaOH}$ concentration was improved to be $0.01 \mathrm{M}$, the peak current achieved the best value. Subsequently, it came to a gradual decrease with increasing $\mathrm{NaOH}$ concentration. Accordingly, during this experiment we chose $0.01 \mathrm{M} \mathrm{NaOH}$ containing $0.09 \mathrm{M} \mathrm{KCl}$ as the supporting electrolyte.

In preparing the sensor, the amount of modifying material on the surface of electrode influences the sensor response to detecting target. Hence, the influence of nano$\mathrm{CuO}$ film thickness on electrode on sensor response to $\mathrm{H}_{2} \mathrm{O}_{2}$ was examined in this paper. The amount of nano- $\mathrm{CuO}$ on the GCE was controlled to be $0.028,0.056,0.085,0.113,0.142$, 
TABLE 1: Performance comparison of the $\mathrm{H}_{2} \mathrm{O}_{2}$ sensors based on different-materials-modified electrodes.

\begin{tabular}{|c|c|c|c|c|}
\hline Material & Linear range $(\mu \mathrm{M})$ & Detection limit (nM) & Sensitivity & Reference \\
\hline MWCNT/Ag nanohybrids & $50 \sim 17000$ & 500 & $1.42 \mu \mathrm{A} \mathrm{mM}^{-1}$ & [24] \\
\hline Nano- $\mathrm{TiO}_{2} / \mathrm{DNA} /$ thionin nanocomposite & $50 \sim 22300$ & 50000 & - & {$[15]$} \\
\hline Nafion and copper oxide nanoparticles & $0.15 \sim 9000$ & 60 & - & {$[10]$} \\
\hline $\mathrm{CuO}$ flower-like nanomaterials & $42.5 \sim 4000$ & 167 & $88.4 \mu \mathrm{A} \mathrm{mM}^{-1} \mathrm{~cm}^{-1}$ & {$[22]$} \\
\hline $\mathrm{CuO}$ shuttlelike nanocrystals & $0.02 \sim 250$ & 7 & $227 \mu \mathrm{A} \mathrm{mM}^{-1}$ & This study \\
\hline
\end{tabular}

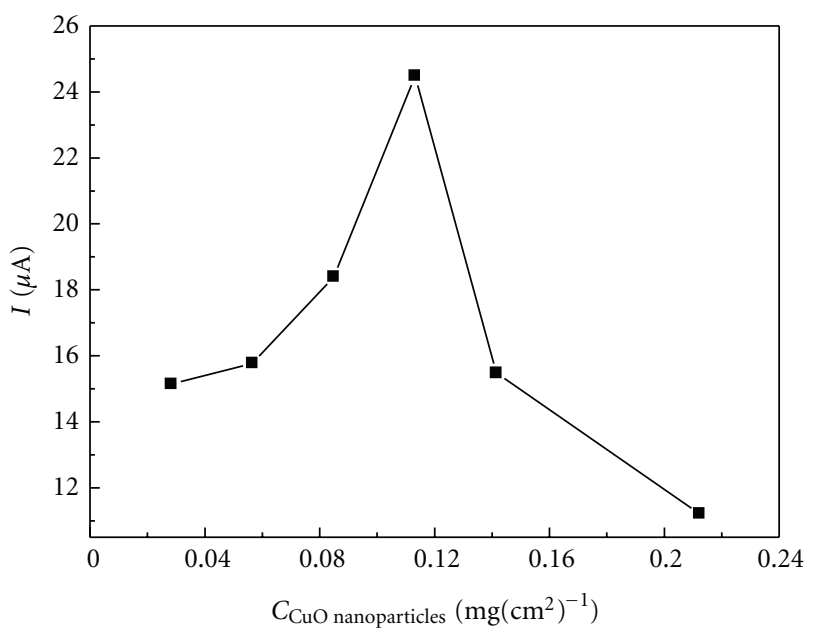

Figure 5: Current response of nano-CuO/GCE for $0.1 \mathrm{mM} \mathrm{H}_{2} \mathrm{O}_{2}$ inside the electrochemical reactor at various modification amounts of nano- $\mathrm{CuO}$ on the electrode, electrolyte: $0.01 \mathrm{M} \mathrm{NaOH}+0.09 \mathrm{M}$ $\mathrm{KCl}$ solution.

and $0.212 \mathrm{mg}\left(\mathrm{cm}^{2}\right)^{-1}$, respectively, and the anodic peak currents of $0.1 \mathrm{mM} \mathrm{H}_{2} \mathrm{O}_{2}$ were measured. The experimental results showed that anodic peak current of $\mathrm{H}_{2} \mathrm{O}_{2}$ increased with the increment of the nano-CuO amount. When the amount of nano-CuO was improved to be $0.113 \mathrm{mg}\left(\mathrm{cm}^{2}\right)^{-1}$, the peak current achieved the best value. Subsequently, it came to a gradual decrease with increasing the nano- $\mathrm{CuO}$ amount (shown in Figure 5). With increasing the amount of nano- $\mathrm{CuO}$ on surface of electrode, the electrocatalytic active area increased, and it also promoted electron transfer in the redox of $\mathrm{H}_{2} \mathrm{O}_{2}$. When the amount of nano- $\mathrm{CuO}$ was in excess of $0.113 \mathrm{mg}\left(\mathrm{cm}^{2}\right)^{-1}$, the conductivity of modified electrode decreased and the anodic peak current of $\mathrm{H}_{2} \mathrm{O}_{2}$ decreased.

3.4. Amperometric Response to $\mathrm{H}_{2} \mathrm{O}_{2}$ and the Calibration Curve. The amperometric response of nano-CuO/GCE upon adding $\mathrm{H}_{2} \mathrm{O}_{2}$ little by little every $50 \mathrm{~s}$ was tested at the applied potential $0.19 \mathrm{~V}$ in $0.01 \mathrm{M} \mathrm{NaOH}$ containing $0.09 \mathrm{M}$ $\mathrm{KCl}$ electrolyte solution with continuous stirring under the optimal conditions. As shown in Figure 6(a), good responses were observed during the successive addition of 2,6 , and $20 \mu \mathrm{M} \mathrm{H}_{2} \mathrm{O}_{2}$, respectively. The response of preparing sensor to low-concentration $\mathrm{H}_{2} \mathrm{O}_{2}$ was shown in Figure 6 (inset b), which demonstrated an effective catalytic property of nano$\mathrm{CuO}$ material. It could be observed that the response current

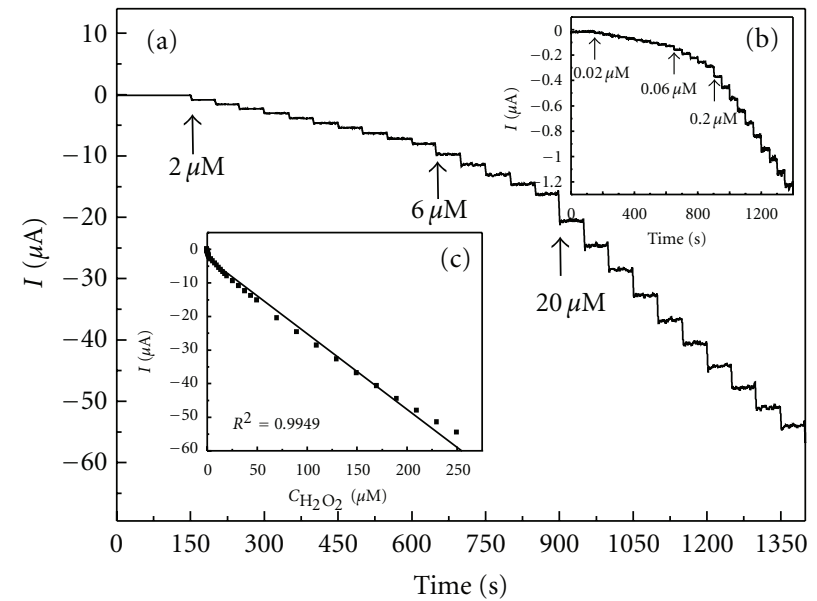

Figure 6: Amperometric current-time curves for $\mathrm{H}_{2} \mathrm{O}_{2}$ oxidation on the nano- $\mathrm{CuO} / \mathrm{GCE}$, at applied potential $0.19 \mathrm{~V}$ (versus $\mathrm{Ag} / \mathrm{AgCl}$ ) in $0.01 \mathrm{M} \mathrm{NaOH}+0.09 \mathrm{M} \mathrm{KCl}$ solution. Concentrations were used in the range between $0.02 \mu \mathrm{M}$ and $250 \mu \mathrm{M} \mathrm{H}_{2} \mathrm{O}_{2}$. (a) the current-time curves for adding $0.02,0.06$, and $0.2 \mu \mathrm{M}$ of $\mathrm{H}_{2} \mathrm{O}_{2}$. (b) the current-time curves for adding 2,6 , and $20 \mu \mathrm{M}$ of $\mathrm{H}_{2} \mathrm{O}_{2}$. (c) showed $I_{\text {pa }}$ versus $C_{\mathrm{H}_{2} \mathrm{O}_{2}}$.

was linear with $\mathrm{H}_{2} \mathrm{O}_{2}$ concentration in the range from 0.02 to $250 \mu \mathrm{M}$. The regression equation was $Y(\mu \mathrm{A})=-1.69-$ $0.227 X(\mu \mathrm{M})$ with the correlation coefficient being 0.995 , and the detection limit was computed to be $7 \mathrm{nM}(S / N=3)$ at a signal-to-noise ratio of 3 . The sensitivity was calculated as $227 \mu \mathrm{AmM}^{-1}$. Such high sensitivity could be attributed to the fact that high-density $\mathrm{CuO}$ shuttlelike nanostructure can greatly increase the electrocatalytic active area and also promote electron transfer in the redox of $\mathrm{H}_{2} \mathrm{O}_{2}$ [22]. Table 1 summarized the dissimilar performance of the $\mathrm{H}_{2} \mathrm{O}_{2}$ sensors based on different-materials-modified electrodes.

The stability and reproducibility of this sensor were also examined. The prepared electrochemical sensor possessed long-term stability because the nano- $\mathrm{CuO}$ material could strongly be adsorbed on surface of glassy carbon electrode. We used this electrochemical sensor to detect $\mathrm{H}_{2} \mathrm{O}_{2}$ several times every day intermittently and also studied the storage stability of the sensor by storing it in air at ambient conditions when not in use. Three days later the response of the sensor maintained $99.2 \%$ and after three weeks the response retained $93.6 \%$ of the original value. This study indicated that nano-CuO/GCE have good stability and it can be used repeatedly. 


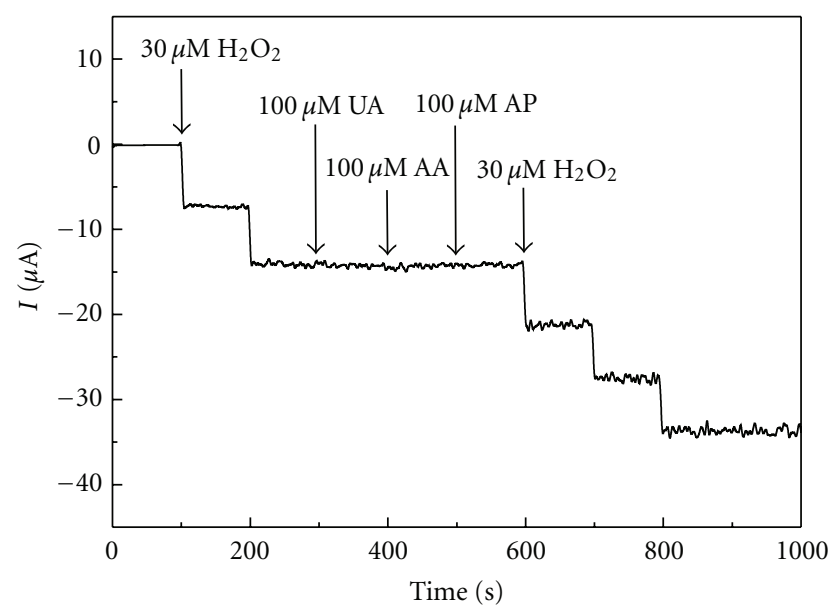

FIGURE 7: Effects of UA, AA, and AP interferences on the amperometric response to $\mathrm{H}_{2} \mathrm{O}_{2}$ in $5 \mathrm{~mL} 0.01 \mathrm{M} \mathrm{NaOH}+0.09 \mathrm{M} \mathrm{KCl}$ solution.

TABle 2: The detection results of $\mathrm{H}_{2} \mathrm{O}_{2}$ concentration in test samples.

\begin{tabular}{lcccc}
\hline Sample & & Added $\left(10^{-4} \mathrm{M}\right)$ & Found $\left(10^{-4} \mathrm{M}\right)$ & Recovery $\%$ \\
\hline \multirow{3}{*}{ Tap water } & 1 & 0.5 & 0.49 & $98 \%$ \\
& 2 & 1 & 0.99 & $99 \%$ \\
& 3 & 2 & 1.95 & $97.5 \%$ \\
\hline
\end{tabular}

3.5. Anti-Interference Ability and Recovery Test of the Sensor. In real samples, some coexisting electroactive species might affect the sensor response. And so three kinds of potential interferences $100 \mu \mathrm{M}$ uric acid (UA), $100 \mu \mathrm{M}$ ascorbic acid (AA), $100 \mu \mathrm{M}$ acetaminophen (AP), were examined, as illustrated in Figure 7. Other some coexisting chemicals were also examined. Those chemicals did not interfere in the detection of hydrogen peroxide. This may be attributed to the fact that detection of hydrogen peroxide was performed in basic conditions in this work. The electroactivity of some chemicals was inhabited.

For verifying the applicability of the nano-CuO-modified GCE for analysis application, recovery experiment was carried out using the modified electrode. Under the optimal conditions, we added $\mathrm{H}_{2} \mathrm{O}_{2}$ into the samples with the concentration of 50,100 , and $200 \mu \mathrm{M}$, respectively. All the measurements were carried out four times. The average recoveries were 98\% $(n=4), 99 \%(n=4)$, and $97.5 \%$ $(n=4)$, respectively. Acceptable recoveries were obtained as shown in Table 2, suggesting that it was feasible to apply the proposed method to quantitatively detect the certain concentration range of $\mathrm{H}_{2} \mathrm{O}_{2}$ in water samples.

\section{Conclusions}

We have successfully fabricated a high-sensitivity, fast-response, and highly selective amperometric $\mathrm{H}_{2} \mathrm{O}_{2}$ sensor based on $\mathrm{CuO}$ nanoshuttles. The shuttlelike $\mathrm{CuO}$ nanoparticles were immobilized onto surface of electrode by absorption and can greatly increase the electrocatalytic active area and also obviously promote electron transfer abilities between $\mathrm{H}_{2} \mathrm{O}_{2}$ molecules and electrode. The nano- $\mathrm{CuO} /$ GCE exhibited the prominent activity for redox of $\mathrm{H}_{2} \mathrm{O}_{2}$, and the fabricated sensor gave a good stability and reproducibility, which could be used as an amperometric sensor for determination of low-concentration $\mathrm{H}_{2} \mathrm{O}_{2}$ in samples.

\section{Acknowledgments}

The authors thank the National Natural Science Foundation of China (Grant no. 20775002) for financial support. The paper was supported by Program for Innovative Research Team in Anhui Normal University.

\section{References}

[1] H. Razmi and H. Heidari, "Amperometric determination of hydrogen peroxide on surface of a novel PbPCNF-modified carbon-ceramic electrode in acidic medium," Journal of Electroanalytical Chemistry, vol. 625, no. 2, pp. 101-108, 2009.

[2] C. Matsubara, N. Kawamoto, and K. Takamura, "Oxo [5,10,15, 20-tetra(4-pyridyl)porphyrinato] titanium(IV): an ultra-high sensitivity spectrophotometric reagent for hydrogen peroxide," The Analyst, vol. 117, no. 11, pp. 1781-1784, 1992.

[3] A. Lobnik and M. Cajlakovic, "Sol-gel based optical sensor for continuous determination of dissolved hydrogen peroxide," Sensors and Actuators B, vol. 74, no. 1-3, pp. 194-199, 2001.

[4] Z. Genfa, P. K. Dasgupta, W. S. Edgemond, and J. N. Marx, "Determination of hydrogen peroxide by photoinduced fluorogenic reactions," Analytica Chimica Acta, vol. 243, no. 2, pp. 207-216, 1991.

[5] G. Y. Shi, J. X. Lu, F. Xu, H. G. Zhou, L. T. Jin, and J. Y. Jin, "Liquid chromatography-Electrochemical detector for the determination of glucose in rat brain combined with in vivo microdialysis," Analytica Chimica Acta, vol. 413, no. 1-2, pp. 131-136, 2000.

[6] U. Pinkernell, S. Effkemann, and U. Karst, "Simultaneous HPLC determination of peroxyacetic acid and hydrogen peroxide," Analytical Chemistry, vol. 69, no. 17, pp. 3623-3627, 1997.

[7] F. R. P. Rocha, E. R. Torralba, B. F. Reis, A. M. Rubio, and M. de la Guardia, "A portable and low cost equipment for flow injection chemiluminescence measurements," Talanta, vol. 67, no. 4, pp. 673-677, 2005.

[8] M. J. Navas, A. M. Jiménez, and G. Galán, "Air analysis: determination of hydrogen peroxide by chemiluminescence," Atmospheric Environment, vol. 33, no. 14, pp. 2279-2283, 1999.

[9] E. C. Hurdis and H. Romeyn Jr., "Accuracy of determination of hydrogen peroxide by cerate oxidimetry," Analytical Chemistry, vol. 26, no. 2, pp. 320-325, 1954.

[10] X. M. Miao, R. Yuan, Y. Q. Chai, Y. T. Shi, and Y. Y. Yuan, "Direct electrocatalytic reduction of hydrogen peroxide based on Nafion and copper oxide nanoparticles modified Pt electrode," Journal of Electroanalytical Chemistry, vol. 612, no. 2, pp. 157-163, 2008.

[11] Y. Zou, L. X. Sun, and F. Xu, "Prussian Blue electrodeposited on MWNTs-PANI hybrid composites for $\mathrm{H}_{2} \mathrm{O}_{2}$ detection," Talanta, vol. 72, no. 2, pp. 437-442, 2007.

[12] W. Z. Le and Y. Q. Liu, "Preparation of nano-copper oxide modified glassy carbon electrode by a novel film plating/potential cycling method and its characterization," Sensors and Actuators B, vol. 141, no. 1, pp. 147-153, 2009. 
[13] M. H. Pournaghi-Azar, F. Ahour, and F. Pournaghi-Azar, "Simple and rapid amperometric monitoring of hydrogen peroxide in salivary samples of dentistry patients exploiting its electro-reduction on the modified/palladized aluminum electrode as an improved electrocatalyst," Sensors and Actuators B, vol. 145, no. 1, pp. 334-339, 2010.

[14] S. A. Kumar and S. M. Chen, "Electrocatalytic reduction of oxygen and hydrogen peroxide at poly(p-aminobenzene sulfonic acid)-modified glassy carbon electrodes," Journal of Molecular Catalysis A, vol. 278, no. 1-2, pp. 244-250, 2007.

[15] H. Xiao, X. Chen, J. X. Zhang, and W. Yang, "Direct electrochemistry of myoglobin in $\mathrm{MnO}_{2}$ nanosheet film," Chemistry Letters, vol. 36, no. 6, pp. 772-773, 2007.

[16] A. Salimi, E. Sharifi, A. Noorbakhsh, and S. Soltanian, "Immobilization of glucose oxidase on electrodeposited nickel oxide nanoparticles: direct electron transfer and electrocatalytic activity," Biosensors \& Bioelectronics, vol. 22, no. 12, pp. 31463153, 2007.

[17] J. Zang, M. L. Chang, X. Cui et al., "Tailoring zinc oxide nanowires for high performance amperometric glucose sensor," Electroanalysis, vol. 19, no. 9, pp. 1008-1014, 2007.

[18] A. Salimi, R. Hallaj, S. Soltanian, and H. Mamkhezri, "Nanomolar detection of hydrogen peroxide on glassy carbon electrode modified with electrodeposited cobalt oxide nanoparticles," Analytica Chimica Acta, vol. 594, no. 1, pp. 24-31, 2007.

[19] R. P. Wijesundera, M. Hidaka, K. Koga, M. Sakai, and W. Siripala, "Growth and characterisation of potentiostatically electrodeposited $\mathrm{Cu}_{2} \mathrm{O}$ and $\mathrm{Cu}$ thin films," Thin Solid Films, vol. 500, no. 1-2, pp. 241-246, 2006.

[20] M. Julian, S. Luis, M. Francisco et al., "Nanostructured CuO thin film electrodes prepared by spray pyrolysis: a simple method for enhancing the electrochemical performance of $\mathrm{CuO}$ in lithium cells," Electrochimica Acta, vol. 49, no. 26, pp. 4589-4597, 2004.

[21] C. B. McAuley, Y. Du, G. G. Wildgoose, and R. G. Compton, "The use of copper(II) oxide nanorod bundles for the nonenzymatic voltammetric sensing of carbohydrates and hydrogen peroxide," Sensors and Actuators B, vol. 135, no. 1, pp. 230235, 2008.

[22] M. J. Song, S. W. Hwang, and D. Whang, "Non-enzymatic electrochemical $\mathrm{CuO}$ nanoflowers sensor for hydrogen peroxide detection," Talanta, vol. 80, no. 5, pp. 1648-1652, 2010.

[23] Y. Zhang, S. Wang, X. Li, L. Chen, Y. Qian, and Z. Zhang, "CuO shuttle-like nanocrystals synthesized by oriented attachment," Journal of Crystal Growth, vol. 291, no. 1, pp. 196-201, 2006.

[24] W. Zhao, H. Wang, X. Qin et al., "A novel nonenzymatic hydrogen peroxide sensor based on multi-wall carbon nanotube/silver nanoparticle nanohybrids modified gold electrode," Talanta, vol. 80, no. 2, pp. 1029-1033, 2009. 


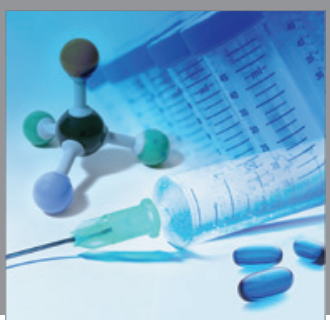

International Journal of

Medicinal Chemistry

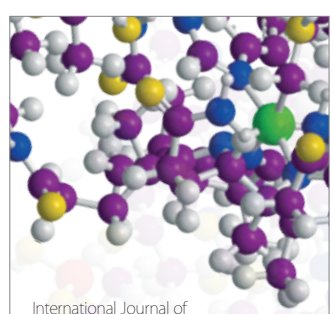

Carbohydrate Chemistry

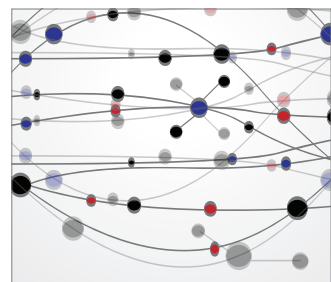

The Scientific World Journal
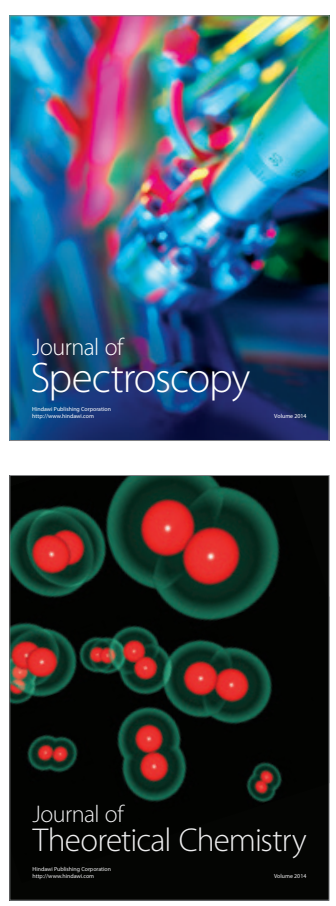
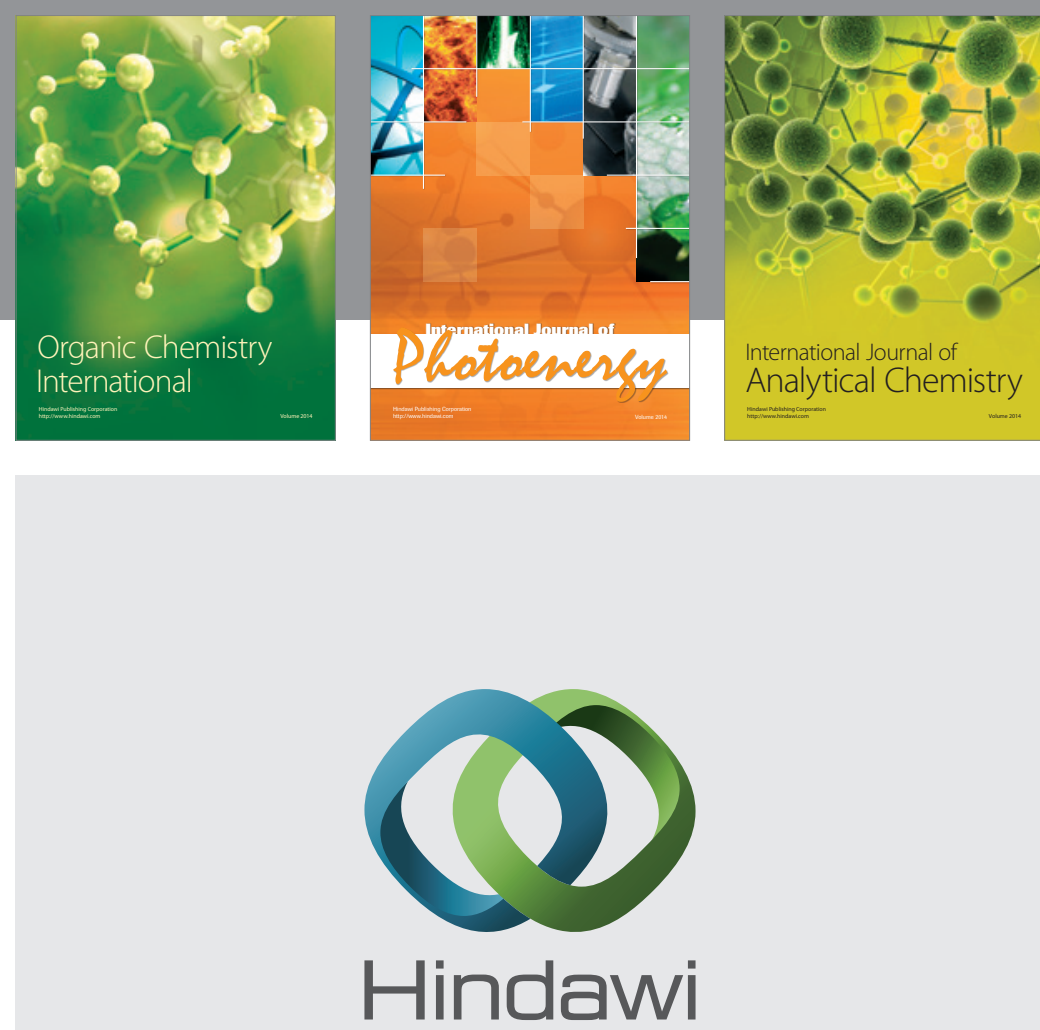

Submit your manuscripts at

http://www.hindawi.com
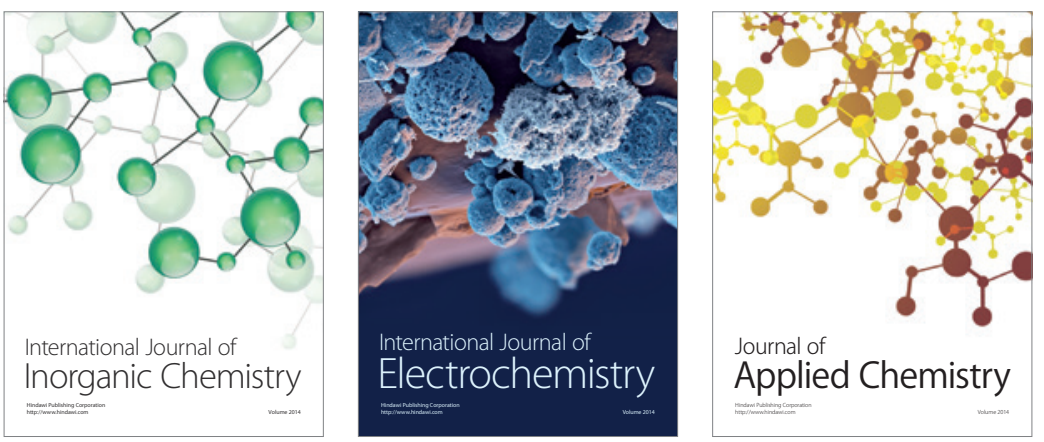

Journal of

Applied Chemistry
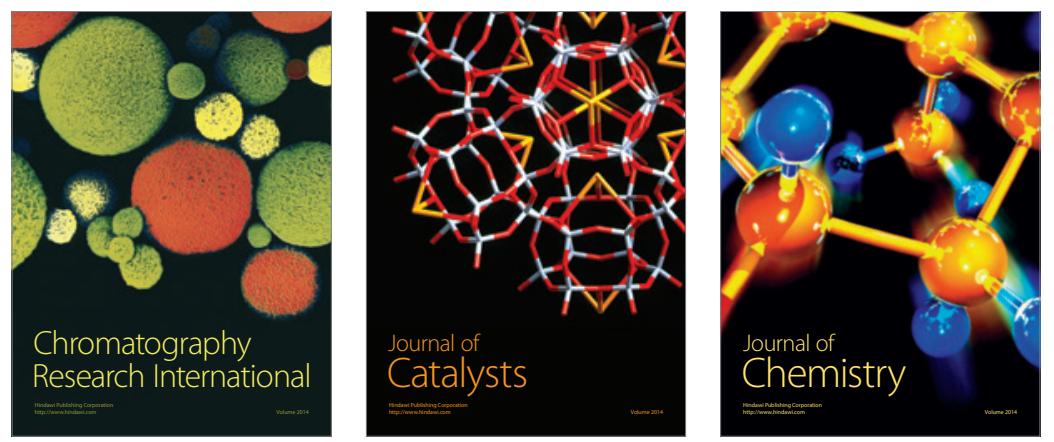
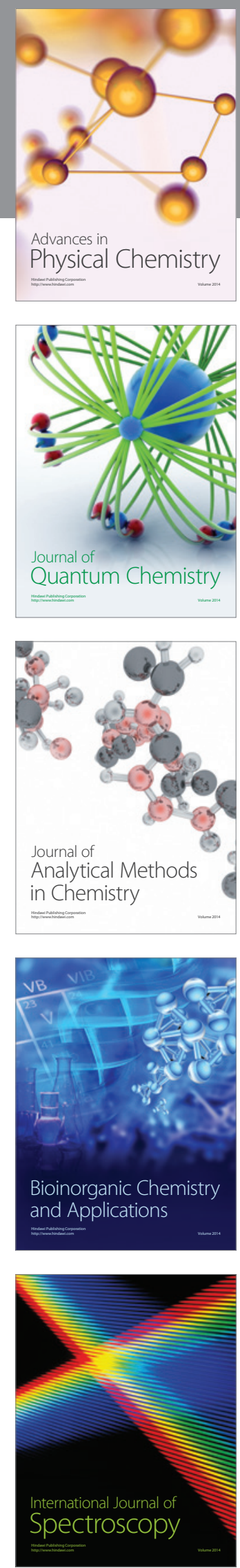